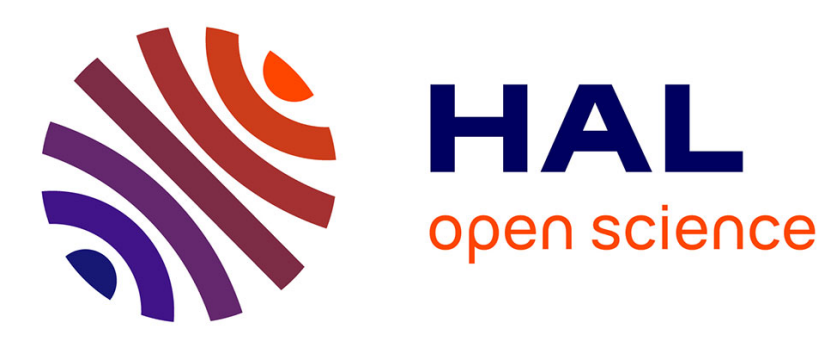

\title{
Transgenic Mouse Reporter to Study Muc5b In Vivo.
} Jean-Luc Desseyn, Céline Portal, Frederic Gottrand, Valérie Gouyer

\section{To cite this version:}

Jean-Luc Desseyn, Céline Portal, Frederic Gottrand, Valérie Gouyer. Transgenic Mouse Reporter to Study Muc5b In Vivo.. Annals of the American Thoracic Society, 2018, Annals of the American Thoracic Society, 15, pp.S149-S153. 10.1513/AnnalsATS.201802-085AW . hal-02149469

\section{HAL Id: hal-02149469 \\ https://hal.univ-lille.fr/hal-02149469}

Submitted on 6 Jun 2019

HAL is a multi-disciplinary open access archive for the deposit and dissemination of scientific research documents, whether they are published or not. The documents may come from teaching and research institutions in France or abroad, or from public or private research centers.
L'archive ouverte pluridisciplinaire HAL, est destinée au dépôt et à la diffusion de documents scientifiques de niveau recherche, publiés ou non, émanant des établissements d'enseignement et de recherche français ou étrangers, des laboratoires publics ou privés. 


\title{
TRANSATLANTIC AIRWAY CONFERENCE \\ Annals of the American Thoracic Society
}

\section{Transgenic Mouse Reporter to Study Muc5b In Vivo}

\author{
Jean-Luc Desseyn ${ }^{1}$, Céline Portal ${ }^{1{ }^{*},}$, Frédéric Gottrand ${ }^{1}$ and Valérie Gouyer ${ }^{1}$
}

1- Univ. Lille, Inserm, CHU Lille, LIRIC UMR 995, F-59000 Lille, France

Correspondence and requests for reprints should be addressed to:

Jean-Luc Desseyn, Ph.D.

Inserm, Université de Lille, CHU Lille, LIRIC UMR 995

Faculté de Médecine, Pôle Recherche, $5^{\text {ème }}$ étage, 1 place de Verdun, F-59000 Lille, France

Tel: (+33) 320627789

e-mail: jean-luc.desseyn@inserm.fr

* Current address: Icahn School of Medicine at Mount Sinai, New York, NY 10029, USA

\section{Competing interests}

The authors declare that they have no competing interests.

Running title: Transgenic reporter mice to study Muc5b in vivo

Ann Am Thorac Soc. 2018 Nov;15(Supplement_3):S149-S153. doi: 10.1513/AnnalsATS.201802-085AW.

\begin{abstract}
Dysregulation of gel-forming mucins is associated with many airway diseases. Better knowledge of the pathophysiological mechanisms linking mucins and respiratory diseases will advance the understanding of their pathogenesis and should provide opportunities to develop new therapeutic compounds for treatment. MUC5B and MUC5AC are the two main gel-forming mucins in the respiratory tract. The organization in domains and the expression profile of mouse Muc5b are very similar to those in humans, which makes the mouse a relevant model for studies of the translational activities of human mucins. To assess the in vivo biological functions of Muc5b, a mouse reporter tagged in frame with the green fluorescent protein marker has been engineered by homologous recombination. The proof of concept that this reporter model may be informative for translational studies was confirmed by the finding that interleukin 13 administration in living mice upregulated Muc5b production.
\end{abstract}

Keywords: airways; mucus; mucins; Muc5b-GFP; interleukin 13; GFP live imaging

The mucus gel that covers airway tissues is a highly heterogeneous mixture made mainly of water $(>90 \%)$ and gel-forming mucins. These mucins are large and complex molecules, and are encoded in humans by five genes: MUC2, MUC5AC, MUC5B, MUC6, and MUC19. These genes are highly conserved in the mouse and are designated as Muc2, Muc5ac, Muc5b, Muc6, and Muc19, respectively. The four genes MUC2, MUC5AC, MUC5B, and MUC6 belong to a cluster of genes on human chromosome 11 band p15.5 (1). The genomic order MUC6/2/5AC/5B and arrangement of the four mucin genes are conserved on mouse chromosome 7 band F5 (2). Muc6 is transcribed from the telomere to centromere and with its orientation opposite to that of the three other mucin genes. A fifth gel-forming mucin, MUC19, is located on human chromosome 12 band q12, and its mouse orthologue is located on chromosome 15 band F1 (3).

These mucins are produced by specialized cells, such as goblet cells, and are stored intracellularly before being released as long polymers, which form more complex structures once in contact with water at the surface of secretory epithelial cells (4). Gel-forming mucins are multidomain proteins that are highly O-glycosylated. Their organization in domains has been 
deduced from cDNA nucleotide sequences. Human MUC5B cDNA and genomic sequences have been fully determined (5-8). Errors in detecting nucleotide sequences and gaps in knowledge about some mucin nucleic sequences may give rise to fallacious interpretations of biological studies.

Many diseases of the secretory epithelium are associated with goblet cell hyperplasia and metaplasia, and an increased production of mucins. However, a decrease in goblet cell density can also be a hallmark of some pathological situations such as dry eye disease for which the goblet cell loss in the eye conjunctiva is reflected by the reduced tear levels of the gel-forming mucin MUC5AC (For review, see Bron et al. (9)). MUC5AC and MUC5B are the two main gel-forming mucins in the human airway. This review focuses on the mouse Muc5b gel-forming mucin and particularly on the recent development and use of a mouse reporter Muc5b-green fluorescent protein (GFP).

\section{Human MUC5B vs Mouse Muc5b}

The organization in domains of the human and mouse orthologous gel-forming mucins MUC5B/Muc5b is very similar (Figure 1). The amino- and carboxy-terminal regions are globular and are necessary for dimerization and oligomerization of the mucin (10). These regions are made of domains found in von Willebrand factor and flank the large central part, which is highly $O$ glycosylated. The amino- and carboxy-regions are 1324 and 808 amino acids (aa) in length in the human and 1330 aa and 798 aa long in the mouse, respectively. The C-terminal cystine knot domain mediates dimerization of MUC5B subunits in the endoplasmic reticulum, and the $\mathrm{N}$ terminal von Willebrand D domain catalyzes disulfide binding in the Golgi apparatus, which creates multimers.

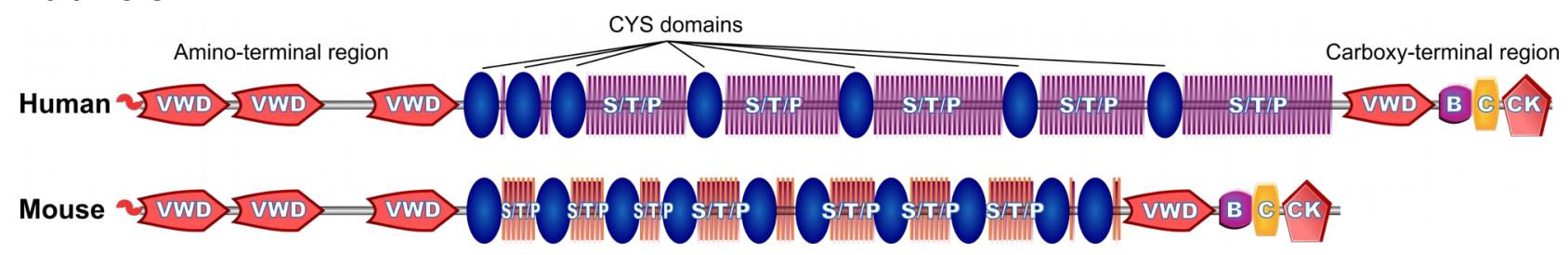

Figure 1. Schematic representation of the human MUC5B and mouse Muc5b peptide showing a similar domain organization. The amino- and carboxy-terminal regions are made of von Willebrand D (VWD), B, C, and cystine knot (CK) domains. The central part is made of CYS domains (blue ovals) interspersed with regions enriched in Ser, Thr, and Pro (S/T/P) that carry the numerous O-glycosylated chains characteristic of mucins. These S/T/P sequences differ in size and sequence between the two organisms.

The O-glycosylated region is made mainly of stretches of peptides enriched in Ser/Thr/Pro (S/T/P regions). The high content of Ser and Thr results in a dense O-glycosylation, which gives the characteristic bottle-brush structure of mucins (11). In humans, S/T/P regions of mucins are made of tandemly repeated (TR) sequences that are different in length and sequence between mucins. Notably, there is no obvious conservation of the S/T/P sequences between human mucin and their mouse or rat orthologues. In addition, the TR consensus sequence is less conserved in the mouse or rat than in the human, which is believed to be the sign of a faster evolutionary process in organisms with a shorter generation time $(2,12,13)$.

TR sequences of mucins exhibit a polymorphism in terms of their number (variable number TRs or VNTRs) between individuals and between the two alleles within the same individual. However, for an unknown reason, this is not the case for MUC5B (14). VNTR polymorphism has not been investigated in inbred and outbred mouse strains, but the size of the central region of mucins might greatly influence the phenotype in mouse disease models. The central region of MUC5B is 3570 aa long encompassing five S/T/P regions ( 2550 aa). The mouse Muc5b central part is shorter and has a predicted size of $\sim 2670$ aa.

The main structural difference between the mouse and human MUC5B orthologous peptides concerns the presence of seven copies in the human and 10 copies in the mouse of a domain named the CYS domain, which is linked with or interrupts stretches of S/T/P (Figure 1). This domain is $\sim 110$ aa long and seems to have been highly conserved during evolution. It has been found in two and nine copies in the two other mucins MUC2 and MUC5AC, respectively (15). 
Data suggest that this domain may be crucial for establishing noncovalent interaction between mucins (for recent review, see (4)).

At the gene level, the two orthologous MUC5B/Muc5b genes are highly similar and are made of 49 exons; exon \#31 is the largest (10713 bp in the human) and encodes the CYS domains and the S/T/P regions. The gene extends over $39.1 \mathrm{~kb}$ and $34 \mathrm{~kb}$ in the human and mouse, respectively. Human and murine promoter sequences seem conserved for only the first 157 nucleotides, which share $67.5 \%$ similarity (16).

Analysis of the MUC5B/Muc5b promoter using reporter gene analysis is sparse, especially in the mouse. The basal promoter activity of human MUC5B seems to reside within its $4.2 \mathrm{~kb}$ DNA fragment upstream of its transcriptional start site (17). Sp1 cis elements within the human MUC5B promoter sequence and within intron \#1 have been shown to be important for MUC5B regulation in epithelial cell lines $(8,17-20)$. An uncharacterized $42-k D a$ protein-binding SP1 site that localizes in a VNTR sequence and is not conserved in the mouse and overlaps one exon and the following intron in the 3' region of MUC5B (21) has been suggested to regulate MUC5B expression or MUC5B mRNA stability in the HT-29 MTX colon cancer cell line (22). The activating transcription factor 1 (ATF-1) binds the MUC5B promoter to stimulate MUC5B expression in the AGS and KATO-III gastric adenocarcinoma cell lines (19). E2 sex hormone has been reported to stimulate MUC5B gene overexpression directly in NCl-H292 cells (23).

Promoter methylation modulates MUC5B expression in cell lines $(19,24)$. MUC5B hypermethylation has been studied in lung tissue from patients with idiopathic pulmonary fibrosis and has been recently associated with the regulation of MUC5B expression and as a risk factor for the development of lung disease (25). In the latter study, a forkhead box protein A2 (FOXA2) site located $3 \mathrm{~kb}$ upstream of the MUC5B transcriptional start site that is conserved in mammals, including rodents, was found to be essential for regulating MUC5B expression. Using quantitative chromosome conformation capture, Gosalia et al. found that CCCTC-binding factor regulates MUC5B expression in a cell type-specific manner (26). Vals and collaborators have shown in differentiated mouse middle ear epithelial cells that Staphylococcus epidermidis lysate stimulates human MUC5B expression and nontypable Haemophilus influenzae lysate can induce mouse Muc5b upregulation via proinflammatory cytokines, such as $\mathrm{Cxcl} 2(27,28)$. The same team has also reported that cigarette smoke condensate increases Muc5b mRNA expression in part via AP-1 NF-KB cis sites within the mouse Muc5b promoter sequence (29).

In the mouse, Muc5b promoter activity has been reported to be completely inhibited by thyroid transcription factor-1 factor but activated by GATA family factors (16). No study has attempted to show that transcriptional factors that regulate the mucin in one species are conserved in its orthologous counterpart, and the current knowledge comes mainly from investigations using cell lines.

\section{Creation of the Mouse Muc5b-GFP Reporter}

Human MUC5B has been shown to be expressed at the mRNA and protein levels in different adult tissues: salivary glands, ear, trachea, lungs, gallbladder, and cervix. Less was known of its expression in the mouse.

To understand the biological role of Muc5b in normal and pathological situations, a mouse Muc5b reporter has been engineered by homologous recombination using a synthetic sequence encoding a monomeric enhanced GFP in frame with Muc5b in place of the unique Stop codon located in exon \#49 (30). The targeting strategy is shown in Figure 2. A Gly-Ser-lle-Ala-Thr linker was placed between the last amino acid in Muc5b and the GFP sequence. This strategy is thought to allow the monitoring of Muc5b trafficking in mice, derived cells, and explants, and the model was designed to provide access to a new conditional knockout model complementary to that created by Evans et al. who targeted the 5' end of Muc5b by homologous recombination (31). To this end, the exons \#48 and \#49 were flanked by LoxP sites in the GFP reporter model.

The transgenic mouse was obtained by standard procedures. G418-resistant colonies were selected based on cell growth and morphology, and were screened by polymerase chain reaction (PCR) analysis. Positive embryonic stem (ES) cell clones were amplified and confirmed by Southern blot analysis using internal and external probes to the targeting vector. One positive ES cell clone was expanded and injected into C57BL/6J blastocysts reimplanted into OF1 pseudo- 
pregnant females. Male chimeras were obtained and were bred with C57BL/6 ubiquitous FLPrecombinase-expressing deleter mice to allow germline excision of the FRT-flanked neomycin selection cassette located just downstream of Muc5b. Successful removal of the cassette was confirmed by PCR and Southern blot analyses. The 'clean' Muc5b-GFP knockin model has been backcrossed for at least 10 generations in the C57BL/6 genetic background and is routinely genotyped by PCR analysis.
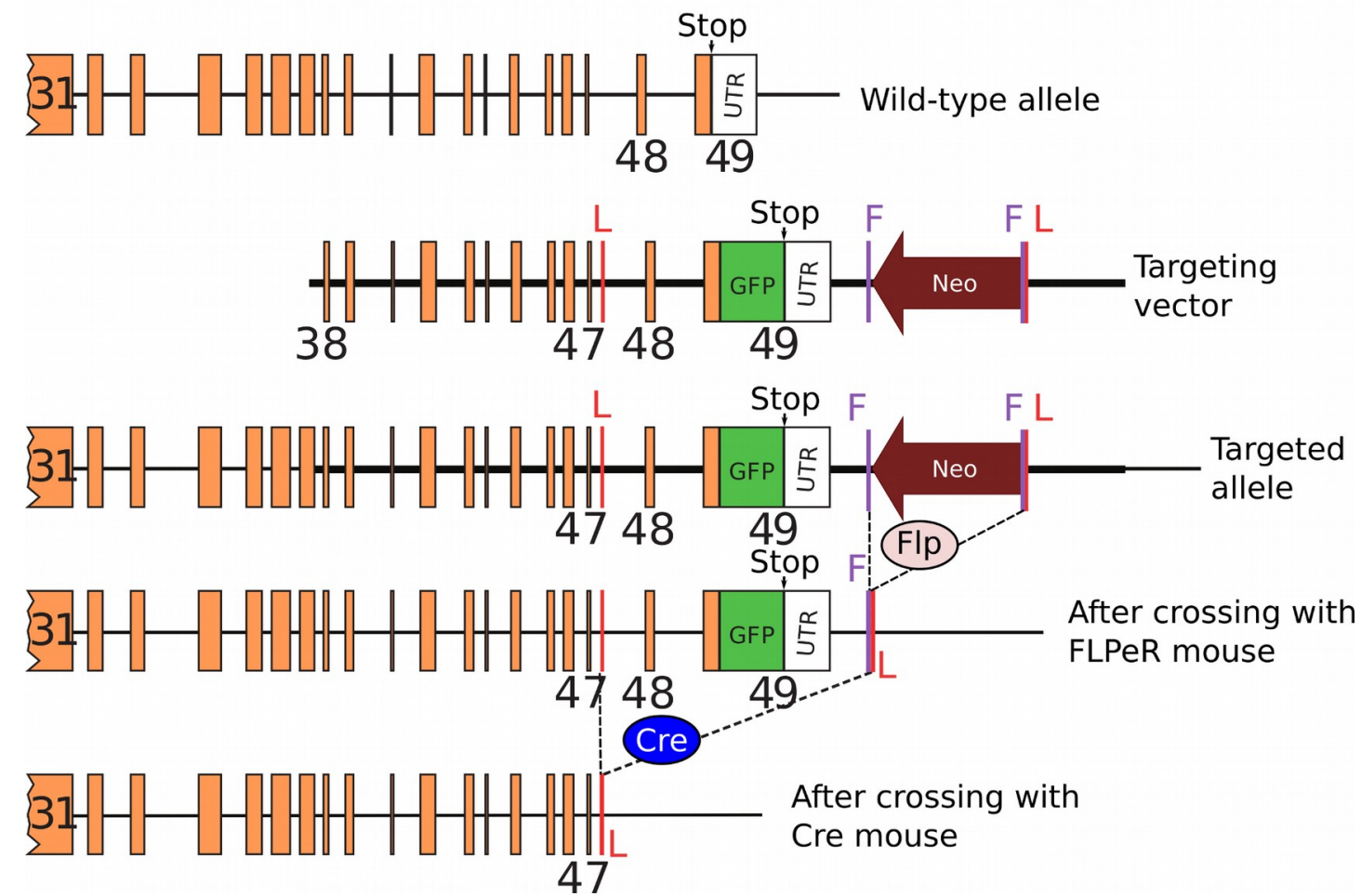

Figure 2. Strategy to target the Muc5b genomic locus. Schematic representation of the 3' end of the wild-type allele, targeted construct (targeted vector), and the 3' end of the targeting allele before and after FLP- and Cre-mediated excision. Some exons are numbered (exon \#31 is the large central exon that encodes the CYS domains and S/T/P regions). A synthetic GFP sequence was inserted in frame of Muc5b in place of the unique Stop codon. A LoxP-FRTneomycin (Neo)-FRT cassette was inserted downstream of Muc5b. A second intronic LoxP site was inserted in intron \#47. Chimeric mice were bred with FLPeR mice to remove the neomycin cassette used for ES cell selection. The resulting Muc5b-GFP mice can be further crossed with Cre recombinase-expressing mice to generate the all-tissue or tissue-specific null Muc5b allele by excision of the two last exons containing the unique 3' untranslated region (UTR) with its unique Stop codon.

\section{Muc5b Expression Pattern}

Immunohistochemistry (IHC) studies were performed using Muc5b-GFP and wild-type mice with a commercial antibody directed against the GFP tag and an in-house antibody directed against a short peptide belonging to a CYS domain of Muc5b. These studies revealed that Muc5b is produced in the trachea, lung, ear, nose, gallbladder, and cervix (30). GFP fluorescence was also clearly observed in fresh tissues from the middle ear, cervix, trachea, nasal cavity, and eye conjunctiva. These findings showed that the expression/production profile of Muc5b is very similar to its human counterpart.

Because Muc5b seemed to be produced by many tissues and cavities accessible by endomicroscopy, the fluorescence of Muc5b-GFP was assessed by probe-based confocal laser endomicroscopy in anesthetized mice using a Cellvizio apparatus. The ultra-thin flexible fibered probe used is made of thousands of microfibers grouped in bundles. Each microfiber excites the GFP at $488 \mathrm{~nm}$ and records the live fluorescent activity as a movie. This method confirmed production of the mucin in the trachea, in the eye conjunctiva, nose, and vagina; in the vagina, the greatest fluorescence was observed just before ovulation, similarly to what has been described in women (32) and in pregnant mice (30). These results suggest that Muc5b is hormonally regulated. 


\section{Monitoring of Muc5b-GFP Production After Pharmacological Treatment}

Interleukin 13 (IL-13) stimulates goblet cell differentiation. In cellular models of the airways or eye conjunctiva and, less often, explant cultures, several independent laboratories have reported that IL-13 upregulates MUC5AC. The few studies that have investigated MUC5B have produced conflicting results. More recently, our study using GFP-tagged mouse Muc5b demonstrated that Muc5b production is produced earlier than though before $(30,33)$ and was stimulated by a single administration of IL-13 to whole lungs explant culture obtained at day embryonic age 12.5 , as measured by fluorescence activity and confirmed by IHC (30). In that study, no modification of Muc5ac was observed by IHC (unpublished observations). In another report where decreased goblet cell density in the eye conjunctiva was chemically induced to mimic dry eye, we found that topical administration of IL-13 upregulated Muc5b and restored the Muc5b-positive goblet cell density (34).

\section{Conclusions and Future Directions}

MUC5B is a major gel-forming mucin in the airways. The gene and its expression pattern and domain architecture are highly conserved in the mouse, which makes the mouse a suitable organism model for assessing the role of the mucin in normal and pathological situations such as asthma, pulmonary fibrosis, airways infection, cystic fibrosis, ear effusion, and rhinitis. The recent development of the mouse GFP-tagged Muc5b reporter offers the opportunity to understand further the biological role in living mice of gel-forming mucin and abnormal Muc5b regulation in respiratory diseases. The next step is to develop immortalized GFP-positive cell lines and organoids to allow in vitro studies, in parallel with in vivo studies, to identify the molecules that modulate goblet cell differentiation and Muc5b expression, production, and release. The monomeric GFP-tag was added at the C-terminus of Muc5b. Homozygous mice are viable and fertile and do not show any abnormality but the correct dimerization of Muc5b-GFP via its C-terminal CK domain remains to be examined. Proteolytic degradation of the MUC5B polypeptide backbone by bacteria has been shown to occur naturally in saliva (35) and extracellular proteolytic degradation of MUC5B has been reported in sputum of cystic fibrosis subjects (10). The macro-molecule organization of MUC5B polymers is now better understood $(10,36-38)$. However, the maturation process of the mouse Muc5b counterpart and Muc5b-GFP is unknown and studies are now needed to examine if the GFP-tag may alter the Muc5b maturation and the mucus rheology.

Because Muc5ac is the other main gel-forming mucin in the airways, engineering of a dual mouse Muc5b-Muc5ac reporter model should be attempted by genetically inserting in frame a non-GFP tag at the carboxy-terminal end of Muc5ac. Genome editing using the CRISPR/Cas9 system might be useful for generating a new reporter using Muc5b-GFP embryos. This method would allow the insertion of a LoxP site at the 3' end of Muc5ac to obtain a double Muc5ac-Muc5b null allele by Cre-mediated excision of the 3' end of Muc5ac and full Muc5b.

\section{References}

1. Pigny P, Guyonnet-Duperat V, Hill AS, Pratt WS, Galiegue-Zouitina S, Collyn-D'Hooghe M, et al. Human mucin genes assigned to 11p15.5: identification and organization of a cluster of genes. Genomics. 1996;38(3):340-52.

2. Desseyn J-L, Laine A. Characterization of mouse Muc6 and evidence of conservation of the gel-forming mucin gene cluster between human and mouse. Genomics. 2003;81(4):433-6.

3. Chen Y, Zhao YH, Kalaslavadi TB, Hamati E, Nehrke K, Le AD, et al. Genome-wide search and identification of a novel gel-forming mucin MUC19/Muc19 in glandular tissues. Am J Respir Cell Mol Biol. 2004;30(2):155-65.

4. Demouveaux B, Gouyer V, Gottrand F, Desseyn J-L, Narita T, Desseyn J-L. Gel-forming mucin interactome drives mucus viscoelasticity. Adv Colloid Interface Sci. 2018;252:69-82.

5. Desseyn J-L, Guyonnet-Dupérat V, Porchet N, Aubert J-P, Laine A, Guyonnet-Duperat V, et al. Human mucin gene MUC5B, the 10.7-kb Large central exon encodes various alternate subdomains resulting in a super-repeat. Structural evidence for a 11p15.5 gene family. J Biol Chem. 1997;272(6):3168-78.

6. Desseyn J-L, Aubert J-P, Van Seuningen I, Porchet N, Laine A. Genomic organization of the 3' region of the human mucin gene MUC5B. J Biol Chem. 1997;272(27):16873-83.

7. Desseyn J-L, Buisine M-P, Porchet N, Aubert J-P, Laine A. Genomic organization of the human mucin gene MUC5B. cDNA and genomic sequences upstream of the large central exon. J Biol Chem. 1998;273(46):30157-64.

8. Chen $\mathrm{Y}$, Zhao YH, Di YP, Wu R. Characterization of human mucin 5B gene expression in airway epithelium and the genomic clone of the amino-terminal and 5'-flanking region. Am J Respir Cell Mol Biol. 2001;25(5):542-53. 
9. Bron AJ, de Paiva CS, Chauhan SK, Bonini S, Gabison EE, Jain S, et al. TFOS DEWS II pathophysiology report. Ocul Surf. 2017;15(3):438-510.

10. Ridley C, Kirkham S, Williamson SJ, Davis CW, Woodman P, Thornton DJ. Biosynthesis of the polymeric gelforming mucin MUC5B. Am J Physiol Lung Cell Mol Physiol. 2016;310(10):L993-1002.

11. Corfield, Livraghi-Butrico A, Fletcher AA, McElwee MM, Evans SE, Boerner RM, et al. Muc5b is required for airway defence. Nature. 2014;505(7483):412-6.

32. Gipson IK, Ho SB, Spurr-Michaud S, Tisdale AS, Zhan Q, Torlakovic E, et al. Mucin genes expressed by human female reproductive tract epithelia. Biol Reprod. 1997;56(4):999-1011.

33. Roy MG, Rahmani M, Hernandez JR, Alexander SN, Ehre C, Ho SB, et al. Mucin production during pre- and postnatal mouse lung development. Vol. 44, Am. J. Respir. Cell Mol Biol. 2011;44(6):755-60.

34. Portal C, Gouyer V, Gottrand F, Desseyn J-L. Preclinical mouse model to monitor live Muc5b-producing conjunctival goblet cell density under pharmacological treatments. PLoS One. 2017;12(3):e0174764.

35. Wickström C, Herzberg MC, Beighton D, Svensäter G. Proteolytic degradation of human salivary MUC5B by dental biofilms. Microbiology. 2009;155(Pt 9):2866-72.

36. Kesimer M, Makhov AM, Griffith JD, Verdugo P, Sheehan JK. Unpacking a gel-forming mucin: a view of MUC5B organization after granular release. Am. J. Physiol Lung Cell Mol. Physiol. 2010;298(1):L15-22.

37. Ridley C, Kouvatsos N, Raynal BD, Howard M, Collins RF, Desseyn J-L, et al. Assembly of the respiratory mucin MUC5B: a new model for a gel-forming Mucin. J Biol Chem. 2014;289(23):16409-20.

38. Trillo-Muyo S, Nilsson HE, Recktenwald C V, Ermund A, Ridley C, Meiss LN, et al. Granule-stored MUC5B mucins are packed by the non-covalent formation of N-terminal head-to-head tetramers. J Biol Chem. 2018 Feb 13;jbc.RA117.001014.A. Eukaryotic protein glycosylation: a primer for histochemists and cell biologists. Histochem Cell Biol. 2017;147(2):119-47.

12. Desseyn J-L, Clavereau I, Laine A. Cloning, chromosomal localization and characterization of the murine mucin gene orthologous to human MUC4. Eur J Biochem. 2002;269(13):3150-9.

13. Desseyn J-L, Buisine M-P, Porchet N, Aubert J-P, Degand P, Laine A. Evolutionary history of the $11 \mathrm{p} 15$ human mucin gene family. J Mol Evol. 1998;46(1):102-6.

14. Vinall LE, Hill AS, Pigny P, Pratt WS, Toribara NW, Gum JR, et al. Variable number tandem repeat polymorphism of the mucin genes located in the complex on 11p15.5. Hum Genet. 1998;102(3):357-66.

15. Desseyn J-L. Mucin CYS domains are ancient and highly conserved modules that evolved in concert. Mol Phylogenet Evol. 2009;52(2):284-92.

16. Jonckheere N, Velghe A, Ducourouble M-P, Copin M-C, Renes IB, Van Seuningen I. The mouse Muc5b mucin gene is transcriptionally regulated by thyroid transcription factor-1 (TTF-1) and GATA-6 transcription factors. FEBS J. 2011;278(2):282-94.

17. Wu DY-C, Wu R, Chen Y, Tarasova N, Chang MMJ. PMA stimulates MUC5B gene expression through an Sp1based mechanism in airway epithelial cells. Am J Respir Cell Mol Biol. 2007;37(5):589-97.

18. Van Seuningen I, Perrais M, Pigny P, Porchet N, Aubert J-P. Sequence of the 5'-flanking region and promoter activity of the human mucin gene MUC5B in different phenotypes of colon cancer cells. Biochem J. 2000;348(3):675-86.

19. Perrais M, Pigny P, Buisine M-P, Porchet N, Aubert J-P, Van Seuningen-Lempire I. Aberrant expression of human mucin gene MUC5B in gastric carcinoma and cancer cells. Identification and regulation of a distal promoter. J Biol Chem. 2001;276(18):15386-96.

20. Wu DY-C, Wu R, Reddy SP, Lee YC, Chang MM-J. Distinctive epidermal growth factor receptor/extracellular regulated kinase-independent and -dependent signaling pathways in the induction of airway mucin $5 \mathrm{~B}$ and mucin 5AC expression by phorbol 12-myristate 13-acetate. Am J Pathol. 2007;170(1):20-32.

21. Desseyn J-L, Rousseau K, Laine A. Fifty-nine bp repeat polymorphism in the uncommon intron 36 of the human mucin gene MUC5B. Electrophoresis. 1999;20(3):493-6.

22. Pigny P, Van Seuningen I, Desseyn J-L, Nollet S, Porchet N, Laine A, et al. Identification of a 42-kDa nuclear factor (NF1-MUC5B) from HT-29 MTX cells that binds to the 3' region of human mucin gene MUC5B. Biochem Biophys Res Commun. 1996;220(1):186-91.

23. Choi HJ, Chung Y-S, Kim HJ, Moon UY, Choi YH, Van Seuningen I, et al. Signal pathway of 17beta-estradiolinduced MUC5B expression in human airway epithelial cells. Am J Respir Cell Mol Biol. 2009;40(2):168-78.

24. Vincent $A$, Perrais $M$, Desseyn J-L, Aubert J-P, Pigny $P$, Van Seuningen I. Epigenetic regulation (DNA methylation, histone modifications) of the 11p15 mucin genes (MUC2, MUC5AC, MUC5B, MUC6) in epithelial cancer cells. Oncogene. 2007;26(45):6566-76

25. Helling BA, Gerber AN, Kadiyala V, Sasse SK, Pedersen BS, Sparks L, et al. Regulation of MUC5B Expression in Idiopathic Pulmonary Fibrosis. Am J Respir Cell Mol Biol. 2017;57(1):91-9. 
26. Gosalia N, Leir S-H, Harris A. Coordinate regulation of the gel-forming mucin genes at chromosome 11p15.5. J Biol Chem. 2013;288(9):6717-25.

27. Val S, Mubeen H, Tomney A, Chen S, Preciado D. Impact of Staphylococcus epidermidis lysates on middle ear epithelial proinflammatory and mucogenic response. J Investig Med. 2015;63(2):258-66.

28. Val S, Kwon H-J, Rose MC, Preciado D. Middle Ear Response of Muc5ac and Muc5b Mucins to Nontypeable Haemophilus influenzae. JAMA Otolaryngol head neck Surg head neck Surg. 2015;141(11):997-1005.

29. Preciado D, Lin J, Wuertz B, Rose M. Cigarette smoke activates NF kappa B and induces Muc5b expression in mouse middle ear cells. Laryngoscope. 2008;118(3):464-71.

30. Portal C, Gouyer V, Magnien M, Plet S, Gottrand F, Desseyn J-L. In vivo imaging of the Muc5b gel-forming mucin. Sci Rep. 2017;7:44591.

31. Roy MG, Livraghi-Butrico A, Fletcher AA, McElwee MM, Evans SE, Boerner RM, et al. Muc5b is required for airway defence. Nature. 2014;505(7483):412-6.

32. Gipson IK, Ho SB, Spurr-Michaud S, Tisdale AS, Zhan Q, Torlakovic E, et al. Mucin genes expressed by human female reproductive tract epithelia. Biol Reprod. 1997;56(4):999-1011.

33. Roy MG, Rahmani M, Hernandez JR, Alexander SN, Ehre C, Ho SB, et al. Mucin production during pre- and postnatal mouse lung development. Vol. 44, Am. J. Respir. Cell Mol Biol. 2011;44(6):755-60.

34. Portal C, Gouyer V, Gottrand F, Desseyn J-L. Preclinical mouse model to monitor live Muc5b-producing conjunctival goblet cell density under pharmacological treatments. PLoS One. 2017;12(3):e0174764.

35. Wickström C, Herzberg MC, Beighton D, Svensäter G. Proteolytic degradation of human salivary MUC5B by dental biofilms. Microbiology. 2009;155(Pt 9):2866-72.

36. Kesimer M, Makhov AM, Griffith JD, Verdugo P, Sheehan JK. Unpacking a gel-forming mucin: a view of MUC5B organization after granular release. Am. J. Physiol Lung Cell Mol. Physiol. 2010;298(1):L15-22.

37. Ridley C, Kouvatsos N, Raynal BD, Howard M, Collins RF, Desseyn J-L, et al. Assembly of the respiratory mucin MUC5B: a new model for a gel-forming Mucin. J Biol Chem. 2014;289(23):16409-20.

38. Trillo-Muyo S, Nilsson HE, Recktenwald C V, Ermund A, Ridley C, Meiss LN, et al. Granule-stored MUC5B mucins are packed by the non-covalent formation of N-terminal head-to-head tetramers. J Biol Chem. 2018 Feb 13;jbc.RA117.001014. 